\title{
Translation and cross-cultural adaptation into Italian of the self-administered FLARE-RA questionnaire for rheumatoid arthritis
}

\author{
N. Ughi' ${ }^{1}$, T. Schioppo', I. Scotti ${ }^{1}$, V. Merlino', A. Murgo', O. De Lucia', \\ B. Fautrel ${ }^{2}$, F. Guillemin ${ }^{3}$, R. Christensen ${ }^{4}$, F. Ingegnoli'1,5 \\ ${ }^{1}$ Division of Clinical Rheumatology, ASST Pini-CTO, Milano, Italy; ${ }^{2}$ Department of Rheumatology, \\ IMIDIATE Clinical Research Network, Pitié Salpêtrière Hospital, Pierre et Marie Curie University, Paris 6, \\ Sorbonne University, GRC-08 (EEMOIS), Paris, France; ${ }^{3}$ Inserm Clinical Epidemiology Center 1433, \\ Brabois University Hospital, Vandoeuvre-lès-Nancy, France; ${ }^{4}$ Musculoskeletal Statistics Unit, \\ The Parker Institute, Bispebjerg and Frederiksberg Hospital \& Department of Rheumatology, \\ Odense University Hospital, Frederiksberg, Denmark; ${ }^{5}$ Department of Clinical Sciences \& Community Health, \\ Università degli Studi di Milano, Milano, Italy
}

\section{SUMMARY}

The aim was to provide a translation into Italian with cross-cultural adaptation of the French FLARE-Rheumatoid Arthritis (RA) questionnaire, and to test its acceptability, feasibility, reliability and construct validity in a single-centre cohort study.

The French version of the FLARE-RA questionnaire was cross-culturally adapted and translated into Italian following an established forward-backward translation procedure, with independent translations and backtranslations. To validate the Italian version we tested the internal validity with Cronbach's alpha, test-retest reliability with the intraclass correlation coefficient, agreement between assessments with Bland-Altman plots and construct validity with Spearman's correlation coefficients.

The questionnaire was tested on 283 consecutive RA outpatients (mean age 56.1 \pm 13.9 years, 226/283 females, median disease duration 12.6 years ranging from 0.2 to 70.6$)$. For the global score (11 items) the Cronbach's alpha coefficient was 0.94 . The intraclass correlation coefficient was 0.87 (95\% CI, 0.76-0.96). The correlation of FLARE-RA global score was 0.59 (95\% CI, 0.50-0.66) with the Disease Activity Score on 28 joints, 0.63 (95\% CI, 0.55-0.71) with the Simplified Disease Activity Index, 0.77 (95\% CI, 0.71-0.83) with the RA Impact of Disease and 0.67 (95\% CI, 0.59-0.73) with the Health Assessment Questionnaire.

The Italian version of the FLARE-RA is feasible, brief and easy to administer. The translated and cross-cultural adapted showed accordingly to be valid and reliable. This questionnaire has some practical advantages, such as clarity, comprehensiveness, simplicity, and a minimum filling time. The development of cross-cultural adapted questionnaires in different languages is of pivotal importance to obtain standardized and comparable data across countries.

Key words: Rheumatoid arthritis; self-administered questionnaire; patient reported outcome measures; flare; disease exacerbation.

\section{INTRODUCTION}

heumatoid arthritis (RA) is a chronic systemic inflammatory disease characterized by joint swelling, pain and stiffness leading to a gradual joint damage and a progressively increasing disability (1). The treat-to-target strategy has proven effective in achieving disease remission (2). However, a number of patients with RA do not reach remission, despite they receive the latest therapies.

A mounting body of evidence suggests that disease flares occur in more than half of the patients and contribute to radiographic damage and disease progression (3-6). It has been demonstrated that disease flares substantially contribute to patient burden, poorer health-related quality of life, disability, healthcare use and costs (6-10). $\overline{\text { Corresponding author: }}$ Nicola Ughi

Division of Clinical Rheumatology, ASST Pini-CTO,

Piazza Cardinal Ferrari, 1 20122 Milano, Italy E-mail: n.ughi@reumatologia.it 
Although disease remission is an important endpoint in clinical trials, lack of consensus on flare definition and measurement makes it challenging. Moreover, due to different cultural backgrounds or different perceptions of the disease, the concept of disease flare may vary between physicians and patients and among patients themselves $(11,12)$.

Over the last few years, increasing attention has been devoted to the patient-centered perspective of the disease by adopting dedicated patient-reported outcomes (PROs) in clinical practice and research setting (13). The use of PROs to quantify disease flares promotes the inclusion of patient perception in the clinical assessment of RA in addition to the physician point of view.

Recently, the self-administered Flare Assessment in Rheumatoid Arthritis (FLARERA) questionnaire has been developed with a modern psychometric method, accounting for patient and physician perspectives in France, and it has been validated in French $(14,15)$. It focuses on episodes of flare reported by patients, which occurred in the past 3 months or since the last clinic visit.

This study aims to provide a translation into Italian with a cross-cultural adaptation of the French FLARE-RA questionnaire. Moreover, we tested its acceptability, feasibility, reliability and construct validity in a single-centre cohort study.

\section{MATERIALS AND METHODS}

\section{Study design}

The study was designed to validate the Italian version of the FLARE-RA questionnaire according to COSMIN (Consensusbased Standards for the Selection of Health Status Measurement Instruments) methodological standards $(16,17)$.

\section{Cultural adaptation and translation}

The French version of the FLARE-RA questionnaire was cross-culturally adapted and translated into Italian following the principles of good practice for the translation and cultural adaptation process for PROs (18). The translation followed an established forward-backward translation procedure, with independent translations and back-translations (19).

\section{Patients}

The study population consisted of all consecutive patients aged $\geq 18$ years who met the 1987 American College of Rheumatology (ACR) (20) and/or 2010 ACR/ European League Against Rheumatism classification criteria (EULAR) (21) for RA referring to the in- and outpatient rheumatology clinic at ASST Pini-CTO in Milan (Italy). All patients had disease duration $\geq 3$ months, and the treatment with disease modifying anti-rheumatic drugs (DMARDs) was ongoing for at least 2 months. Overlap syndrome patients (RA overlapping with systemic sclerosis, systemic lupus erythematosus, mixed connective tissue disease, Sjögren's syndrome, dermatomyositis or polymyositis) were excluded. Moreover, RA patients who were unable to comply with protocol recommendations, including language issues (i.e. reading, comprehension, speaking, and use of Italian), were excluded.

\section{Collected data}

Demographic data, RA features, RA disease activity (DAS28-CRP - Disease Activity Score in 28 joints using C-reactive protein and SDAI - Simplified Disease Activity Index), ongoing RA treatment, patient's and physician's global health assessments (visual analog scale - VAS - from $0=$ best to $10=$ worst) were collected $(22,23)$. In particular, the ad-hoc forms included: date of birth, gender, weight, height, education, native language, region of residence, citizenship, age at disease onset, erythrocyte sedimentation rate, CRP, positivity for rheumatoid factor and/or anti-citrullinated protein antibodies, presence of structural damage on radiographs (presence or absence of erosions), ongoing and past conventional and biologic DMARDs, on-going symptomatic therapy (corticosteroids, non-steroidal anti-inflammatory drugs).

Moreover, patients were required to fill out the Health Assessment Questionnaire (HAQ) (24) and the Rheumatoid Arthritis Impact of Disease (RAID) scale (25). 
The Italian version of the FLARE-RA questionnaire was administered to all patients. Each statement was then graded by a patient on a numerical rating scale from 0 (completely untrue) to 10 (absolutely true). The FLARE-RA questionnaire was then re-tested in a subset of patients in order to assess its reproducibility.

\section{Statistical analysis}

Distributions and missing data were evaluated, and descriptive statistics were calculated. For each item, the subscales and the total score were calculated and floor and ceiling effects were evaluated based on the proportions of participants who gave the highest and lowest scores, respectively. The degree to which the questionnaire produced unidimensional scores was assessed by Cronbach's alpha (internal consistency). For test-retest reliability, randomly selected stable patients were asked to complete the questionnaire again after the first administration (this time frame was chosen to avoid memory bias). On the basis of the test-retest data, reliability was calculated using the intraclass correlation coefficient (ICC) from the two different times and a two-way mixed effects model was used. Agreement between the assessments was also explored visually by the use of Bland-Altman plots and the smallest detectable difference $(=1.96 x$ standard deviation of the mean difference between scores) was calculated.

To assess the construct validity, the degree to which scores from the questionnaire correlated with other disease activity assessments and PROs (convergent validity) was studied by Spearman's correlation coefficients. The internal consistency, intraobserver variability and construct validity were assessed for the model based on 11 items and the two subscales.

For the comparison between two mean scores of questionnaires from known groups of interest (patient's self-identification of current flaring status, and remission/ low versus moderate/high disease activity using DAS28-CRP) Cohen's d was used as effect size.

The sample size was determined with the aim of assessing the correlation between the disease activity measures and PROs. A correlation of 0.1 was considered to be negligible (null correlation) against the alternative correlation of 0.25 (difference $0.15)$. The estimated sample size was 261 for a one-sided one-sample correlation test with a type I error alpha $=0.05$ and a power of $80 \%$.

Analyses were performed using StataCorp. 2017, Stata Statistical Software Release 15 (College Station, TX: StataCorp LLC); $p$ values $<0.05$ were considered statistically significant.

\section{RESULTS}

\section{Translation and cultural adaptation}

The translation and cultural adaptation were performed by three physicians (F.I., N.U. and T.S.), one professional translator who was not a physician (L.G.), one native French speaker fluent in Italian (B.C.) and one Italian patient representative fluent in French (P.C.) (Figure 1). At first, the original French version was independently translated into Italian by N.U. and L.G. Then, the two Italian versions were independently translated back by B.C. and P.C.. To ascertain if the back-translations were

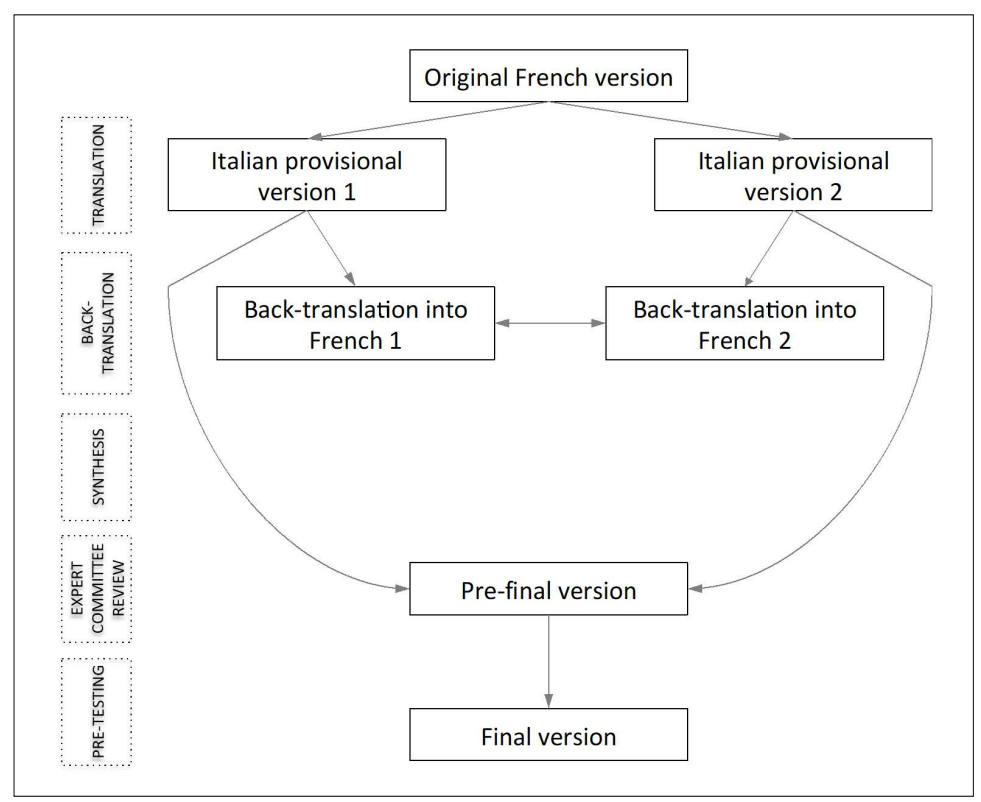

Figure 1 - The process of translation and cultural adaptation into Italian of the original French FLARE-RA questionnaire. 
Table I - The FLARE-RA self-administered questionnaire in Italian.

Questionario FLARE-RA (autosomministrato)

Informazioni prima della compilazione del questionario: questo questionario è stato creato in modo tale da essere compilato sia dal paziente sia dal medico che raccoglie le risposte alle domande.

Indichi in che misura nel corso degli ultimi tre mesi (o dopo l'ultima visita) secondo lei le affermazioni qui sotto riportate sono vere (per favore segni il numero più appropriato).

1. Ha notato la comparsa o il peggioramento della rigidità articolare mattutina per più giorni di seguito.

\begin{tabular}{|l|l|l|l|l|l|l|l|l|l|l|l|l|}
\hline Assolutamente falso & 0 & 1 & 2 & 3 & 4 & 5 & 6 & 7 & 8 & 9 & 10 & $\begin{array}{c}\text { Assolutamente } \\
\text { vero }\end{array}$ \\
\hline
\end{tabular}

2. Ha notato la comparsa o il peggioramento del dolore in una o più articolazioni per più giorni di seguito.

\begin{tabular}{|l|l|l|l|l|l|l|l|l|l|l|l|l|}
\hline Assolutamente falso & 0 & 1 & 2 & 3 & 4 & 5 & 6 & 7 & 8 & 9 & 10 & $\begin{array}{c}\text { Assolutamente } \\
\text { vero }\end{array}$ \\
\hline
\end{tabular}

3. Ha notato la comparsa o il peggioramento del gonfiore in una o più articolazioni per più giorni di seguito.

\begin{tabular}{|l|l|l|l|l|l|l|l|l|l|l|l|l|}
\hline Assolutamente falso & 0 & 1 & 2 & 3 & 4 & 5 & 6 & 7 & 8 & 9 & 10 & $\begin{array}{c}\text { Assolutamente } \\
\text { vero }\end{array}$ \\
\hline
\end{tabular}

4. Ha notato la comparsa o il peggioramento dei risvegli per più notti di seguito a causa del dolore dell'artrite.

\begin{tabular}{|c|c|c|c|c|c|c|c|c|c|c|c|c|}
\hline Assolutamente falso & 0 & 1 & 2 & 3 & 4 & 5 & 6 & 7 & 8 & 9 & 10 & $\begin{array}{c}\text { Assolutamente } \\
\text { vero }\end{array}$ \\
\hline
\end{tabular}

5. Pensa che l'artrite sia peggiorata in modo netto per più giorni di seguito.

\begin{tabular}{|l|l|l|l|l|l|l|l|l|l|l|l|l|}
\hline Assolutamente falso & 0 & 1 & 2 & 3 & 4 & 5 & 6 & 7 & 8 & 9 & 10 & $\begin{array}{c}\text { Assolutamente } \\
\text { vero }\end{array}$ \\
\hline
\end{tabular}

6. Ha aumentato l'assunzione di medicinali contro il dolore (analgesici o anti-infiammatori) per più giorni consecutivi (se non assume alcun farmaco contro il dolore, selezioni "Assolutamente falso").

\begin{tabular}{|l|l|l|l|l|l|l|l|l|l|l|l|l|}
\hline Assolutamente falso & 0 & 1 & 2 & 3 & 4 & 5 & 6 & 7 & 8 & 9 & 10 & $\begin{array}{c}\text { Assolutamente } \\
\text { vero }\end{array}$ \\
\hline
\end{tabular}

\section{Ha aumentato la sua assunzione di cortisone per più giorni di seguito a causa della sua artrite} (se non assume cortisone, selezioni "Assolutamente falso").

\begin{tabular}{|l|l|l|l|l|l|l|l|l|l|l|l|l|}
\hline Assolutamente falso & 0 & 1 & 2 & 3 & 4 & 5 & 6 & 7 & 8 & 9 & 10 & $\begin{array}{c}\text { Assolutamente } \\
\text { vero }\end{array}$ \\
\hline
\end{tabular}

8. Si è sentita/o molto stanca/o per più giorni di seguito a causa della sua artrite.

\begin{tabular}{|l|l|l|l|l|l|l|l|l|l|l|l|l|}
\hline Assolutamente falso & 0 & 1 & 2 & 3 & 4 & 5 & 6 & 7 & 8 & 9 & 10 & $\begin{array}{c}\text { Assolutamente } \\
\text { vero }\end{array}$ \\
\hline
\end{tabular}

\section{9. È stata/o così limitata/o che non poteva "fare più niente" per più giorni di seguito a causa della sua artrite.}

\begin{tabular}{|l|l|l|l|l|l|l|l|l|l|l|l|l|}
\hline Assolutamente falso & 0 & 1 & 2 & 3 & 4 & 5 & 6 & 7 & 8 & 9 & 10 & $\begin{array}{c}\text { Assolutamente } \\
\text { vero }\end{array}$ \\
\hline
\end{tabular}

10. Si è sentita/o più irritabile del solito per più giorni di seguito a causa della sua artrite.

\begin{tabular}{|l|l|l|l|l|l|l|l|l|l|l|l|l|}
\hline Assolutamente falso & 0 & 1 & 2 & 3 & 4 & 5 & 6 & 7 & 8 & 9 & 10 & $\begin{array}{c}\text { Assolutamente } \\
\text { vero }\end{array}$ \\
\hline
\end{tabular}

\section{Si è sentita/o depressa/o per più giorni di seguito a causa della sua artrite.}

\begin{tabular}{|l|l|l|l|l|l|l|l|l|l|l|l|l|}
\hline Assolutamente falso & 0 & 1 & 2 & 3 & 4 & 5 & 6 & 7 & 8 & 9 & 10 & $\begin{array}{c}\text { Assolutamente } \\
\text { vero }\end{array}$ \\
\hline
\end{tabular}

12. Ha avuto voglia di rinchiudersi in se stessa/o o di isolarsi per più giorni di seguito a causa della sua artrite.

Assolutamente falso

\begin{tabular}{|l|l|l|l|l|l|l|l|l|l|l|l|}
0 & 1 & 2 & 3 & 4 & 5 & 6 & 7 & 8 & 9 & 10 & $\begin{array}{c}\text { Assolutamente } \\
\text { vero }\end{array}$ \\
\hline
\end{tabular}

13. Ha provato un maggior bisogno di aiuto per più giorni di seguito a causa della sua artrite.

\begin{tabular}{|l|l|l|l|l|l|l|l|l|l|l|l|l|}
\hline Assolutamente falso & 0 & 1 & 2 & 3 & 4 & 5 & 6 & 7 & 8 & 9 & 10 & $\begin{array}{c}\text { Assolutamente } \\
\text { vero }\end{array}$ \\
\hline
\end{tabular}


nearly identical to the source document, F.G. cross-checked whether the two backtranslations matched the original French questionnaire. Finally, the two Italian versions were pooled to a common version. The pre-final Italian version was then pretested on 5 patients with RA to ascertain that there were no problems with acceptance and comprehension of the questionnaire content or phrasing. The final version of the questionnaire is shown in Table I.

\section{Feasibility, study population and FLARE-RA item statistics}

Before starting the study, a debriefing on clarity of questions and time employed was conducted with 5 people with RA. Then, the study included 283 patients whose characteristics are shown in Table II.

The descriptive statistics of the 13 items of the original FLARE-RA model are shown in Table III. Missing data for each item were very few (maximum $2.8 \%$ for the item on steroid intake increase) and only $2 / 283$ $(0.7 \%)$ scores could not be calculated due to the excess of missing data as recommended by the developers ( $>2$ missing items). The distributions of the items were right skewed and the lowest values were reported for the item on steroid intake increase since the rating 0 (i.e. the lack of steroid use) was reported by half of the patients $(54.4 \%)$. Thus, the floor effect was maximal for this item, and lower than $40 \%$ for the other items. The ceiling effect was not substantial $(<10 \%)$ for any item. With regards to the FLARE-RA (sub)scales, the median (range) values of scores were $3.6(0-10)$ for the 11-item global scale, $4.0(0-10)$ for the 5-item arthritis-related subscale, and 2.7 (010) for the 6-item general subscale.

\section{Internal consistency}

As in the original version, the calculation of the FLARE-RA score was based on an arithmetic mean of 11,5 , and 6 items for the global, arthritis-related, and general score, respectively, without any weighting. The Cronbach's alpha coefficient for internal consistency was 0.94 for the global score, 0.91 for the arthritis-related subscale, and 0.93 for the general subscale.
Table II - Characteristics of the 283 patients with Rheumatoid Arthritis included in the study.

\begin{tabular}{|c|c|}
\hline \multicolumn{2}{|l|}{ Demographics } \\
\hline Age, years, mean (sd) & $56.1(13.9)$ \\
\hline Gender, female (\%) & $226 / 283(79.9)$ \\
\hline $\mathrm{BMI}, \mathrm{kg} / \mathrm{m}^{2}$, median (range) & $23.6(14.4-42.1)$ \\
\hline \multicolumn{2}{|l|}{ Education, $\mathrm{n}(\%)$} \\
\hline Primary school & $34(12.7)$ \\
\hline Secondary school & $63(23.6)$ \\
\hline High school & $102(38.2)$ \\
\hline University & $68(25.5)$ \\
\hline Citizenship, Italian, n (\%) & $278 / 283(98.2)^{\wedge}$ \\
\hline Region of residence, Lombardy, $n$ (\%) & $255 / 283(90.1)^{\S}$ \\
\hline \multicolumn{2}{|l|}{$\begin{array}{c}\text { RA features } \\
\end{array}$} \\
\hline Disease duration, years, median (range) & $12.6(0.25-70.6)$ \\
\hline Serum ACPA+, n (\%) & $136 / 283(48.1)$ \\
\hline Serum RF+, n (\%) & $146 / 283(51.6)$ \\
\hline Erosive disease on $\mathrm{X}$-ray, $\mathrm{n}(\%)$ & $123 / 218(56.4)$ \\
\hline \multicolumn{2}{|l|}{$\begin{array}{r}\text { RA disease activity } \\
\end{array}$} \\
\hline Swollen joint count, $n$, median (range) & $0(0-26)$ \\
\hline Tender joint count, $n$, median (range) & $0(0-26)$ \\
\hline Patient's global assessment (0 - 10 VAS), mean (sd) & $3.1(2.0)$ \\
\hline Physician's global assessment (0 - 10 VAS), mean (sd) & $2.4(2.8)$ \\
\hline ESR, mm/hour, median (range) & $14(0-104)$ \\
\hline CRP, mg/liter, median (range) & $1.5(0-93)$ \\
\hline DAS28-CRP, mean (sd) & $2.4(1.1)$ \\
\hline Remission (DAS28-CRP <2.4), n (\%) & $163 / 277(58.8)$ \\
\hline Low Disease Activity (2.4<DAS28-CRP $\leq 2.9), \mathrm{n}(\%)$ & $35 / 277(12.6)$ \\
\hline Moderate Disease Activity (2.9<DAS28-CRP $\leq 4.6), \mathrm{n}(\%)$ & $63 / 277(22.7)$ \\
\hline High Disease Activity (DAS28-CRP >4.6), n (\%) & $16 / 277(5.8)$ \\
\hline SDAI score $(0-86)$, mean (sd) & $9.3(10.0)$ \\
\hline RAID score $(0-10)$, mean $(s d)$ & $3.1(2.6)$ \\
\hline $\mathrm{HAQ}$ score $(0-3)$, mean $(\mathrm{sd})$ & $0.58(0.66)$ \\
\hline \multicolumn{2}{|l|}{$\begin{array}{ll}\text { Ongoing RA treatment } \\
\end{array}$} \\
\hline Steroids, $n(\%)$ & $128 / 283(45.2)$ \\
\hline Prednisone equivalent dose, mg per day, mean (sd) & $4.6(2.4)$ \\
\hline NSAIDs, n (\%) & $60 / 283(21.2)$ \\
\hline Conventional synthetic DMARD monotherapy, n (\%) & 108/283 (38.2) \\
\hline $\begin{array}{l}\text { Conventional synthetic DMARD combined with biologic } \\
\text { DMARD, } n(\%)\end{array}$ & $74 / 283(26.1)$ \\
\hline Biologic DMARD monotherapy, $\mathrm{n}(\%)$ & $69 / 283(24.4)$ \\
\hline
\end{tabular}

^non-Italian: 1 Bosnia, 1 Croatia, 1 Peru, 2 Romania; Sextra-Lombardy: 13 northern Italy, 3 central Italy, 12 southern Italy; sd: standard deviation; n: number; BMI: body mass index; RA: Rheumatoid Arthritis; ACPA: anti-citrullinated protein antibody; RF: rheumatoid factor; VAS: visual analogue scale; ESR: erythrocyte sedimentation rate; CRP: C-reactive protein; DAS28-CRP: Disease Activity Score in 28 joints using C-reactive protein; SDAl: Simplified Disease Activity Index; RAID: Rheumatoid Arthritis Impact of Disease; HAQ: Health Assessment Questionnaire; NSAIDs: non-steroidal anti-inflammatory drugs; DMARD: disease-modifying antirheumatic drug. 
Table III - Distributions of the 13 items and the FLARE-RA global and subscale scores at baseline.

\begin{tabular}{|c|c|c|c|c|}
\hline Item & Mean (sd) & Median (range) & Floor effect, $\mathrm{n}(\%)$ & Ceiling effect, $\mathrm{n}(\%)$ \\
\hline \multicolumn{5}{|l|}{ Domain } \\
\hline 1. Stiffness & $4.4(3.2)$ & $4(0-10)$ & 50/281 (17.8) & $25 / 281(8.9)$ \\
\hline 2. Sleep & $3.6(3.2)$ & $2(0-10)$ & $75 / 281(26.7)$ & $20 / 281(7.1)$ \\
\hline 3. Swelling & $4.5(3.2)$ & $4(0-10)$ & $53 / 282(18.8)$ & $22 / 282(7.8)$ \\
\hline 4. Pain & $5.1(3.2)$ & $6(0-10)$ & $41 / 281(14.5)$ & $27 / 281(9.5)$ \\
\hline 5. Overall & $3.5(3.0)$ & $2(0-10)$ & $71 / 280(25.4)$ & $18 / 280(6.4)$ \\
\hline 6. Analgesics & $3.2(3.4)$ & $2(0-10)$ & $111 / 281(39.5)$ & $16 / 281(5.7)$ \\
\hline 7. Steroid & $2.1(3.1)$ & $0(0-10)$ & $154 / 275(56.0)$ & $16 / 275(5.8)$ \\
\hline 8. Fatigue & $4.6(3.1)$ & $6(0-10)$ & 48/281 (17.1) & $21 / 281(7.5)$ \\
\hline 9. Limit & $2.7(2.7)$ & $2(0-10)$ & 92/281 (32.7) & 10/281 (3.6) \\
\hline 10. Irritability & $3.7(3.1)$ & $2(0-10)$ & $65 / 283(23.0)$ & $19 / 283(6.7)$ \\
\hline 11. Mood & $3.4(3.0)$ & $2(0-10)$ & $74 / 283(26.1)$ & $15 / 283(5.3)$ \\
\hline 12. Withdrawal & $2.8(2.9)$ & $2(0-10)$ & 92/283 (32.5) & $14 / 283(4.9)$ \\
\hline 13. Help & $3.2(3.1)$ & $2(0-10)$ & 80/282 (28.4) & $16 / 282(5.7)$ \\
\hline \multicolumn{5}{|l|}{ FLARE-RA } \\
\hline Global scale (11 items*) & $3.7(2.4)$ & $3.6(0-10)$ & $18 / 281(6.4)$ & $1 / 281(0.3)$ \\
\hline Arthritis subscale $\left(5\right.$ items $\left.{ }^{\wedge}\right)$ & $4.1(2.7)$ & $4.0(0-10)$ & $26 / 282(9.2)$ & $3 / 282(1.1)$ \\
\hline General symptoms subscale (6 items $\left.{ }^{\S}\right)$ & $3.4(2.6)$ & $2.7(0-10)$ & $35 / 282(12.4)$ & $3 / 282(1.1)$ \\
\hline
\end{tabular}

${ }^{*}$ Excluded items: 5. overall, 7. Steroid; ^Included items: 1. stiffness, 2. sleep, 3. swelling, 4. pain, 6. Analgesics; §Included items: 8. fatigue, 9. limit, 10. irritability, 11. mood, 12. withdrawal, 13. help; n: number; sd: standard deviation; RA, rheumatoid arthritis.

\section{Reliability}

Fifteen patients repeated the questionnaire in two times (14 \pm 7 days after the first administration). The ICC was excellent with 0.87 (95\% confidence interval - CI 0.76$0.96), 0.77$ (95\% CI 0.63-0.92), and 0.79 (95\% CI 0.66-0.93) for the global, arthritis-related, and general subscales, respectively. The Bland-Altman plot for the total score showed $1 / 15$ points $(6.7 \%)$ outside the confidence interval; the mean (standard deviation) difference between the 2 measures was 0.24 (1.0), for a smallest detectable difference of 1.0 .

\section{Construct validity}

The FLARE-RA total score and the 2 subdomain scores showed high correlation with the 6 outcome measures collected at the same time as the FLARE-RA questionnaire (Table IV). The strength of correlation between FLARE-RA scores and the DAS28-CRP was moderate in the whole population and in the subgroup of patients with moderate/high disease activity (rho 0.51-0.59, and 0.54-0.60), yet it was low in the subgroup which had low disease activity or a remission (rho 0.36-0.40). Similar coefficients were observed when SDAI was considered. The correlation was substantially high with RAID which evaluated the disease impact: it showed a moderate to high correlation both in the whole and in the stratified population according to disease activity (rho 0.68-0.77). The correlation was moderate with HAQ, which was used to explore functional limitations (i.e. disease activity and disease-related irreversible damage). Moreover, FLARE-RA showed a moderate correlation with patient's global assessment, but a low to negligible correlation was identified with the physician's global assessment (Table IV). Finally, the mean scores of the FLARE-RA questionnaires were higher in those patients who identified themselves as having a flare compared to those patients who did not with large effect sizes (Table V). When 
Table IV - Correlations of FLARE-RA total scores and subscales with measures of disease activity, disease impact, functional limitations, and patient's and physician's global assessments.

\begin{tabular}{|c|c|c|c|}
\hline & $\begin{array}{l}\text { Global scale } \\
\text { (11 items) } \\
\text { rho (Cl) }\end{array}$ & $\begin{array}{c}\text { Arthritis } \\
\text { Subscale (5 items) } \\
\text { rho (CI) }\end{array}$ & $\begin{array}{c}\text { General symptoms } \\
\text { Subscale (6 items) } \\
\text { rho (CI) }\end{array}$ \\
\hline \multicolumn{4}{|l|}{ Whole population, $\mathrm{n}=277$} \\
\hline DAS28-CRP & $0.59(0.50-0.66)$ & $0.59(0.50-0.66)$ & $0.51(0.42-0.60)$ \\
\hline SDAI & $0.63(0.55-0.71)$ & $0.64(0.55-0.71)$ & $0.55(0.46-0.64)$ \\
\hline RAID & $0.77(0.71-0.83)$ & $0.68(0.60-0.74)$ & $0.75(0.68-0.80)$ \\
\hline $\mathrm{HAQ}$ & $0.67(0.59-0.73)$ & $0.58(0.49-0.66)$ & $0.66(0.58-0.73)$ \\
\hline Patient's global (0 - 10 VAS) & $0.69(0.63-0.75)$ & $0.63(0.55-0.70)$ & $0.67(0.60-0.73)$ \\
\hline Physician's global (0 - 10 VAS) & $0.44(0.34-0.54)$ & $0.46(0.37-0.55)$ & $0.36(0.26-0.47)$ \\
\hline \multicolumn{4}{|c|}{ Patients in Remission / Low Disease Activity, $\mathrm{n}=198$} \\
\hline DAS28-CRP & $0.40(0.27-0.51)$ & $0.36(0.23-0.49)$ & $0.37(0.23-0.48)$ \\
\hline SDAl & $0.51(0.39-0.61)$ & $0.48(0.37-0.59)$ & $0.45(0.33-0.57)$ \\
\hline RAID & $0.71(0.61-0.78)$ & $0.59(0.47-0.68)$ & $0.71(0.63-0.78)$ \\
\hline $\mathrm{HAQ}$ & $0.58(0.48-0.69)$ & $0.46(0.33-0.57)$ & $0.59(0.49-0.68)$ \\
\hline Patient's global (0 - 10 VAS) & $0.63(0.55-0.71)$ & $0.54(0.42-0.62)$ & $0.62(0.54-0.70)$ \\
\hline Physician's global (0 - 10 VAS) & $0.25(0.11-0.38)$ & $0.30(0.15-0.41)$ & $0.17(0.03-0.30)$ \\
\hline \multicolumn{4}{|c|}{ Patients in Moderate / High Disease Activity, $\mathrm{n}=79$} \\
\hline DAS28-CRP & $0.60(0.43-0.72)$ & $0.57(0.42-0.70)$ & $0.54(0.34-0.70)$ \\
\hline SDAl & $0.52(0.34-0.67)$ & $0.53(0.35-0.67)$ & $0.45(0.26-0.63)$ \\
\hline RAID & $0.71(0.56-0.83)$ & $0.58(0.38-0.73)$ & $0.73(0.59-0.83)$ \\
\hline $\mathrm{HAQ}$ & $0.63(0.46-0.76)$ & $0.53(0.31-0.68)$ & $0.65(0.47-0.79)$ \\
\hline Patient's global (0 - 10 VAS) & $0.58(0.35-0.73)$ & $0.54(0.35-0.70)$ & $0.56(0.33-0.72)$ \\
\hline Physician's global (0 - 10 VAS) & $0.25(0.04-0.44)$ & $0.26(0.05-0.45)$ & $0.21(-0.02-0.43)$ \\
\hline
\end{tabular}

Correlation coefficients are reported as Spearman's rho. Cl: bootstrap Confidence Intervals based on 1000 bootstrap resamples with bias-corrected method. DAS28-CRP: Disease Activity Score in 28 joints using C-reactive protein; SDAl: Simplified Disease Activity Index; RAID: Rheumatoid Arthritis Impact of Disease; HAQ: Health Assessment Questionnaire; VAS: visual analogue scale; n: number.

stratification for disease activity was considered (DAS28-CRP: remission/low vs moderate/high), significant differences in FLARE-RA scores were observed for total and subscales.

\section{DISCUSSION AND CONCLUSIONS}

Our results showed that the Italian version of FLARE-RA has a good degree of construct validity, with unidimensional scores (consistent), and proved to be a reliable instrument to measure disease flares in patients with RA; namely, the Italian version showed similar results as compared to the French version concerning internal consistency, reproducibility and convergent validity.
The Italian and the French cohort (15) were similar by age and gender distribution. By contrast, in the French cohort $(n=138)$ more patients with an aggressive RA subset (i.e. anti-citrullinated protein antibodies, rheumatoid factor, erosions on X-ray, HAQ) were included compared to the Italian cohort $(n=283)$. As expected in our cohort, the percentage of remission was higher $(59 \%$ vs. $41 \%)$ and fewer patients were treated with biologics. In our study DAS28 was calculated considering CRP, whereas in the French version ESR was used.

The measurement properties of the questionnaire were comparable in the two cohorts. Particularly, this study showed that the FLARE-RA questionnaire had excellent feasibility and reliability, and high 
Table V - FLARE-RA scores by flare status using 2 patient-reported definitions of flare (presence with and without quantification of severity and duration) and by disease activity score in 28 joint.

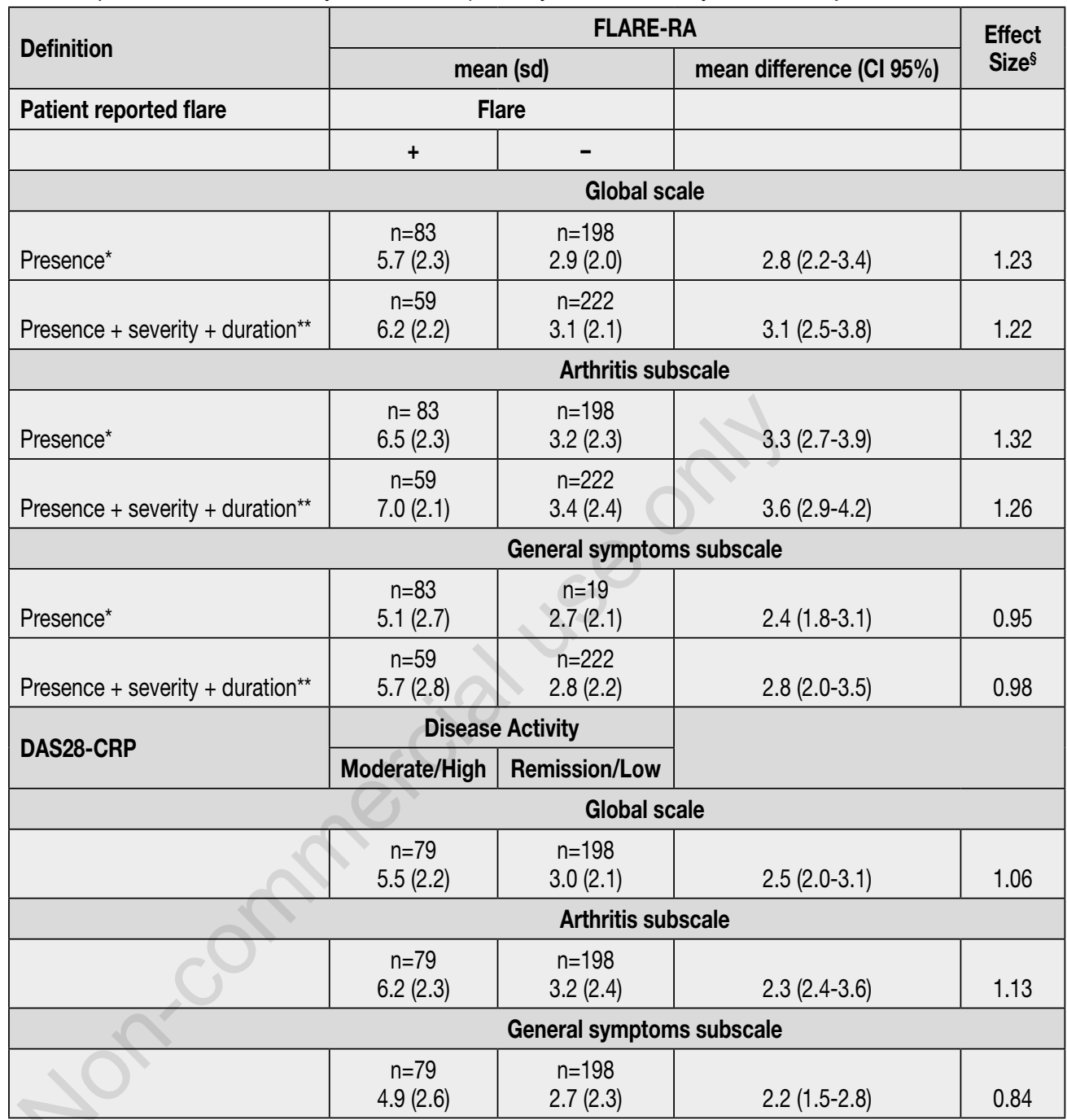

\$Cohen d statistic. *Patients answered "yes" to the question "Are you having a flare at this time?"; ${ }^{* *}$ Patient reported flare AND patient-rated severity $>4 / 10$ AND reported duration $>7$ days. DAS28-CRP: Disease Activity Score in 28 joints using C-reactive protein; Cl: confidence interval.

convergent validity with other indices of disease activity (DAS28-CRP, HAQ, and RAID scores) measured at the same time. The highest correlation was found between the FLARE-RA questionnaire and RAID. This finding is consistent with the patient-derived composite nature of the the RAID score which assesses the seven most important domains of impact of RA (25). Then, the FLARE-RA did correlate well with DAS28-CRP, particularly in patients with moderate/high disease activity. In the Italian cohort, the convergence between
FLARE-RA and SDAI was studied for the first time and a moderate correlation was observed both in the whole population and when stratification by disease activity was considered. These results are comparable with DAS28-CRP and consistent with the known degree of agreement between SDAI and DAS28-CRP scores in clinical practice (26). A moderate correlation with HAQ was observed in the Italian cohort as well as in the French one and this finding is consistent with the association of HAQ score with flares in RA patients (27). 
Our study has some limitations. First, the disease flare is related to a change of the disease activity over time (past 3 months or since the last clinic visit) and the convergent validity was studied with current disease activity assessment. However, the effect sizes were large, when the FLARERA scores were compared between groups with two different patient self-definitions of flare. Secondly, this cohort was from a monocentric study from northern Italy and geographical specificities could have been marginally taken into account, although these differences may be negligible.

In conclusion, the incorporation of validated RA measures like FLARE-RA to identify the disease flare into a practice's workflow is expected to facilitate the adherence to the ACR/EULAR guidelines for the treatment of RA, which include concepts of treat-totarget and tight control. The development and validation of multiple-language versions of existing validated questionnaires play a key role in standardizing the outcome measures collected in trials and prospective cohort studies. The Italian version of the FLARE-RA is feasible since it is brief and easy to administer, and appears to be valid and reliable now also in Italian. In addition, this questionnaire has some practical advantages such as clarity, comprehensiveness, simplicity, and minimum filling time.

\section{Compliance with ethical standards}

All procedures performed in the study complied with the Declaration of Helsinki and its subsequent amendments. The local ethical committee (Comitato Etico Milano Area B, Italy) granted ethical approval (818_2017). Written informed consent was obtained individually from all participants prior to their inclusion in the study.

\section{Funding information}

No specific funding was received from any funding bodies in the public, commercial or not-for-profit sectors to carry out the work described in this text.

\section{Disclosures}

The Parker Institute, Bispebjerg and Frederiksberg Hospital (RC) is supported by a core grant from the Oak Foundation (OCAY-13-309).

\section{Acknowledgements}

The Authors acknowledge Laura Guerrini, Bella Claudie and Patrizia Crespi for their support in the translation and cross-cultural adaptation of the questionnaire.

\section{REFERENCES}

1. Smolen JS, Aletaha D, Redlich K. The pathogenesis of rheumatoid arthritis: New insights from old clinical data? Nat Rev Rheumatol. 2012; 8: 235-43.

2. Smolen JS, Landewe R, Bijlsma J, et al. Eular recommendations for the management of rheumatoid arthritis with synthetic and biological disease-modifying antirheumatic drugs: 2016 update. Ann Rheum Dis. 2016; 76: 96077.

3. Bartlett SJ, Bykerk VP, Cooksey R, et al. Feasibility and domain validation of rheumatoid arthritis (RA) flare core domain set: Report of the OMERACT 2014 RA flare group plenary. J Rheumatol. 2015; 42: 2185-9.

4. Bykerk VP, Shadick N, Frits M, et al. Flares in rheumatoid arthritis: Frequency and management. A report from the BRASS registry. J Rheumatol. 2014; 41: 227-34.

5. Lie E, Woodworth TG, Christensen R, et al. OMERACT RA Flare Working Group. Validation of OMERACT preliminary rheumatoid arthritis flare domains in the NOR-DMARD study. Ann Rheum Dis. 2014; 73: 1781-7.

6. Markusse IM, Dirven L, Gerards AH, et al. Disease flares in rheumatoid arthritis are associated with joint damage progression and disability: 10-year results from the BeSt study. Arthritis Res Ther. 2015; 17: 232.

7. van der Maas A, den Broeder AA. Measuring flares in rheumatoid arthritis. (Why) do we need validated criteria? J Rheumatol. 2014; 41: 189-91.

8. Hewlett S, Sanderson T, May J, et al. 'I'm hurting, I want to kill myself': Rheumatoid arthritis flare is more than a high joint count-an international patient perspective on flare where medical help is sought. Rheumatology (Oxford). 2012; 51: 69-76.

9. Myasoedova E, Chandran A, Ilhan B, et al. The role of rheumatoid arthritis (RA) flare and cumulative burden of RA severity in the risk of cardiovascular disease. Ann Rheum Dis. 2016; 75: 560-5.

10. Kuijper TM, Lamers-Karnebeek FB, Jacobs $\mathrm{JW}$, et al. Flare rate in patients with rheumatoid arthritis in low disease activity or remission when tapering or stopping synthetic 
or biologic DMARD: A systematic review. J Rheumatol. 2015; 42: 2012-22.

11. Alten R, Pohl C, Choy EH, et al. OMERACT RA Flare Definition Working Group. Developing a construct to evaluate flares in rheumatoid arthritis: A conceptual report of the OMERACT RA flare definition working group. J Rheumatol. 2011; 38: 1745-50.

12. Bingham CO 3rd, Alten R, Bartlett SJ, et al. OMERACT RA Flare Definition Working Group. Identifying preliminary domains to detect and measure rheumatoid arthritis flares: Report of the OMERACT 10 RA flare workshop. J Rheumatol. 2011; 38: 1751-8.

13. Her M, Kavanaugh A. Patient-reported outcomes in rheumatoid arthritis. Curr Opin Rheumatol. 2012; 24: 327-34.

14. Berthelot JM, De Bandt M, Morel J, et al. STPR group of French Society of Rheumatology. A tool to identify recent or present rheumatoid arthritis flare from both patient and physician perspectives: The 'FLARE' instrument. Ann Rheum Dis. 2012; 71: 1110-6.

15. Fautrel B, Morel J, Berthelot JM, et al. STPR Group of the French Society of Rheumatology. Validation of FLARE-RA, a self-administered tool to detect recent or current rheumatoid arthritis flare. Arthritis Rheumatol. 2017; 69: 309-19.

16. Mokkink LB, Terwee CB, Knol DL, et al. The COSMIN checklist for evaluating the methodological quality of studies on measurement properties: A clarification of its content. BMC Med Res Methodol. 2010; 10: 22.

17. Mokkink LB, Terwee CB, Gibbons E, et al. Inter-rater agreement and reliability of the COSMIN (COnsensus-based Standards for the selection of health status Measurement Instruments) checklist. BMC Med Res Methodol. 2010; 10: 82.

18. Guillemin F, Bombardier C, Beaton D. Cross-cultural adaptation of health-related quality of life measures: Literature review and proposed guidelines. J Clin Epidemiol. 1993; 46: 1417-32.
19. Epstein J, Osborne RH, Elsworth GR, et al. Cross-cultural adaptation of the health education impact questionnaire: Experimental study showed expert committee, not back-translation, added value. J Clin Epidemiol. 2015; 68: 360-9.

20. Arnett FC, Edworthy SM, Bloch DA, et al. The american rheumatism association 1987 revised criteria for the classification of rheumatoid arthritis. Arthritis Rheum. 1988; 31: 315-24.

21. van der Heijde D, van der Helm-van Mil AH, Aletaha D, et al. EULAR definition of erosive disease in light of the 2010 ACR/EULAR rheumatoid arthritis classification criteria. Ann Rheum Dis. 2013; 72: 479-81.

22. Prevoo ML, van't Hof MA, Kuper HH, et al. Modified disease activity scores that include twenty-eight-joint counts. Development and validation in a prospective longitudinal study of patients with rheumatoid arthritis. Arthritis Rheum. 1995; 38: 44-8.

23. Smolen JS, Breedveld FC, Schiff MH, et al. A simplified disease activity index for rheumatoid arthritis for use in clinical practice. Rheumatology (Oxford). 2003; 42: 244-57.

24. Fries JF, Spitz PW, Young DY. The dimensions of health outcomes: The health assessment questionnaire, disability and pain scales. J Rheumatol. 1982; 9: 789-93.

25. Gossec L, Paternotte S, Aanerud GJ, et al. Finalisation and validation of the rheumatoid arthritis impact of disease score, a patientderived composite measure of impact of rheumatoid arthritis: A EULAR initiative. Ann Rheum Dis. 2011; 70: 935-42.

26. Rintelen B, Sautner J, Haindl PM, et al. Comparison of three rheumatoid arthritis disease activity scores in clinical routine. Scand $\mathbf{J}$ Rheumatol. 2009; 38: 336-41.

27. Bechman K, Tweehuysen L, Garrood T, et al. Flares in rheumatoid arthritis patients with low disease activity: Predictability and association with worse clinical outcomes. J Rheumatol 2018; 45: 1515-21. 